\title{
SOJA, MILHO E ARROZ NO VERÃO, EM ROTAÇÃO COM CROTALÁRIA JÚNCEA NO OUTONO-INVERNO - PERÍODO DE 1999 A 2001
}

\author{
Hipólito Assunção Antônio Mascarenhas (1,5) \\ Emílio Sakai (2) \\ Roberto Tetsuo Tanaka ${ }^{(1,5)}$ \\ Antônio Lúcio Mello Martins ${ }^{(3)}$ \\ Elaine Bahia Wutke ${ }^{(1)}$ \\ Regina Célia de Matos Pires (2) \\ Quirino Augusto de Camargo Carmello ${ }^{(4)}$ \\ Nelson Bortoletto (3)
}

\section{RESUMO}

Em experimentação realizada nos anos agrícolas de 1999/2000 e 2000/2001, na Estação Experimental de Agronomia de Pindorama, SP, do Instituto Agronômico (IAC), num Argissolo Vermelho Amarelo eutrófico degradado, avaliou-se o efeito da rotação de culturas na absorção de nutrientes e no rendimento de grãos de soja, milho e arroz no verão, utilizando-se a Crotalaria juncea L. como adubo verde, no outono-inverno. Verificaram-se efeitos positivos da rotação nos rendimentos de arroz e milho e decréscimo nos mesmos em sistema de monocultivo. $\mathrm{Na}$ cultura da soja não houve resposta à rotação. O teor elevado de $\mathrm{Mn}$ observado nas folhas de arroz e de soja não foi suficientemente prejudicial à produtividade dessas culturas, havendo indício de tolerância dos cultivares utilizados a esse elemento.

Palavras-chave: soja, milho, arroz, adubo verde, rotação, rendimento, tolerância a Mn.

(1)Centro de Análise e Pesquisa Tecnológica de Agronegócio de Grãos e Fibras -IAC.

(2) Centro de Ecofisiologia e Biofísica - IAC.

(3)Núcleos e Estações Experimentais de Agronomia.

(4)Departamento de Solos e Nutrição de Plantas - ESALQ/USP.

(5)Bolsista do CNPq. 


\section{ABSTRACT}

\section{SOYBEANS, MAIZE AND RICE IN ROTATION CULTURE WITH GREEN MANURE CROP IN AUTUMN-WINTER SEASONS - PERIOD FROM 1999 UNTIL 2001}

Experimentation was conducted during two consecutive years (1999/2000 and 2000/2001) at the Experimental Station of Pindorama, SP.of Instituto Agronômico (IAC) in a Dark Red Podzolic soil. The objective was to study the evaluation of rotation, absorption of nutrients and the yield of grains of soybeans, corn and rice in the summer and utilizing the green manure crop Crotalária juncea in autumn -winter.The results showed a positive effect of rotations on the yield of rice and corn and decreasing yield in the system of monoculture. There was no response to rotation for soybeans. The manganese concentration in the leaves of rice and soybeans was in toxic quantities but did not affect the yields, showing that IAC-165 and IAC-Foscarin-31 (rice and soybean cultivar) are tolerant to manganese toxicity

Key words: soybeans, corn, rice, Crotalaria juncea, rotation, yield, tolerance to manganese.

\section{INTRODUÇÃO}

Para a obtenção de elevados índices de produtividade e rentabilidade econômica numa atividade agrícola é fundamental a manutenção e até o incremento da capacidade produtiva da área por meio de um manejo racional do solo. No Estado de São Paulo, com uma agricultura tradicional predominantemente de monocultivo, foi ocasionado um acentuado processo de degradação do solo, particularmente pelo não cumprimento dessa premissa. Entende-se por manejo racional do solo o sistema de associação de práticas agrícolas (conservação do solo e água, calagem, rotação de culturas e adubos verdes), dentre outras, que podem ser utilizadas para o aumento e manutenção da sua capacidade produtiva (Wutke, 1998).

Aproximadamente $20 \%$ dos solos do Estado de São Paulo são Argissolos Vermelho Amarelos, eutróficos ou distróficos de textura are- 
nosa/média, de ocorrência principalmente na região noroeste. Apresentam boa fertilidade natural mas, quando em monocultivos prolongados, a produtividade das culturas é drasticamente reduzida. Isso se deve sobretudo a efeitos alelopáticos e da erosão do solo, em conseqüência do relevo ondulado, do gradiente textural entre os horizontes A e B e do manejo no plantio convencional.

Nessa região do Estado há proprietários com áreas entre 5 a 100 hectares, as quais foram cultivadas com café nos anos 50 a 70. Devido à degradação do solo, à severa incidência de pragas como o nematóide formador de galha (Meloidogyne incognita), com consequiente redução na produtividade, além dos baixos preços do café auferidos nos anos 70, essa cultura foi praticamente erradicada, sendo substituída pelas de algodão, maracujá e citros, entre outras, com as quais, entretanto, e na maioria das áreas, não se obteve o sucesso almejado. Ressalte-se, ainda, o agravamento do problema erosivo nas áreas cultivadas com o algodão, sendo que, em muitos casos, o uso da terra para fins agrícolas foi inviabilizado. Mais recentemente, intensificou-se o cultivo de videiras finas de mesa, com os cultivares Itália e Rubi, porém, se fazem necessárias outras opções de cultivo, tendo em vista a extensão da área agrícola disponível.

Como são escassas as informações sobre o manejo adequado desses solos para culturas anuais, é de relevante importância a realização de estudos dessa natureza, com o objetivo de se estabelecerem sistemas de produção sustentáveis para a agricultura, com vistas à manutenção e ou à restauração da capacidade produtiva dos mesmos.

\section{MATERIAL E MÉTODOS}

A experimentação foi desenvolvida na Estação Experimental de Agronomia de Pindorama, SP, do Instituto Agronômico- IAC, durante dois anos agrícolas consecutivos (1999/2000 e 2000/2001), num solo Argissolo Vermelho Amarelo eutrófico, textura arenosa/média (Embrapa, 1999).

$\mathrm{Na}$ análise química das amostras de solo da camada arável, com base na média de 48 parcelas e antes da instalação do experimento, fo- 
ram determinados os valores 4,1 de $\mathrm{pH}\left(\mathrm{CaCl}_{2}\right) ; 24 \%$ de saturação por bases (V\%); 37,6 mg.dm ${ }^{-3}$ de P e 1,04; 3,5 e 1,4 $\mathrm{mmol}_{\mathrm{c}} \mathrm{dm}^{-3}$, respectivamente para $\mathrm{K}, \mathrm{Ca}$ e $\mathrm{Mg}$. Na correção do solo, utilizou-se calcário dolomítico em quantidade suficiente para elevação da saturação por bases a $50 \%$.

O delineamento experimental utilizado foi o de blocos ao acaso, com quatro repetições. Os tratamentos e sistemas de rotação adotados estão apresentados na Tabela 1 . A parcela de $6 \mathrm{~m}$ de largura e $8 \mathrm{~m}$ de comprimento teve 10 linhas espaçadas $0,6 \mathrm{~m}$ entre si para arroz, crotalária e soja, e 6 linhas espaçadas de 1,0 m para milho.

Utilizaram-se os cultivares IAC-165 de arroz, Cargill 701 de mi1ho, IAC-Foscarin-31 de soja e IAC-1 de crotalária júncea, todos tolerantes à acidez (Camargo \& Camargo 1985; Cargill 1996; Mascarenhas et $a l ., 1990)$, o que permitiu a correção da saturação por bases do solo para apenas $50 \%$, como mencionado acima.

As culturas graníferas foram semeadas sempre na primavera, em outubro de 1999 e de 2000 e a crotalária, no fim de fevereiro e início de março de 1999 e 2000, de acordo com o esquema de rotação apresentado (Tabelas 1 e 2). Excepcionalmente, a crotalária foi substituída pela mucuna preta (Mucuna aterrima), no segundo ano, devido a uma severa incidência de nematóide do gênero Meloidogyne. A densidade populacional estabelecida por metro de linha foi de 54 plantas de arroz, 18 de soja e crotalária e 7 de milho por metro linear.

$\mathrm{Na}$ adubação básica na semeadura aplicaram-se $400 \mathrm{~kg} \cdot \mathrm{ha}^{-1}$ da fórmula 4-20-20, em todas as culturas, à exceção do adubo verde (C. juncea), cultivado sem aplicação de fertilizantes. Foi ainda realizada adubação nitrogenada em cobertura para os cultivos de milho e de arroz, na dosagem de 80 e $40 \mathrm{~kg} \cdot h \mathrm{ha}^{-1}$ de $\mathrm{N}$ respectivamente, na forma de sulfato de amônio, aos 40 dias após a emergência.

Para a obtenção de boa uniformidade de emergência e de estabelecimento das plantas, para serem evitados estresses acentuados durante o desenvolvimento e florescimento das mesmas e, ainda, como garantia da produção, os experimentos foram irrigados por aspersão sempre que necessário. 
Tabela 1. Esquema dos sistemas de rotação de culturas em Pindorama, SP.

\begin{tabular}{cccc}
\hline Sistema de rotação & Tratamentos & $1999 / 2000$ & $2000 / 2001$ \\
\hline \multirow{2}{*}{$\mathrm{I}$} & $\mathrm{l}$ & $\mathrm{S} / \mathrm{C}$ & $\mathrm{A} / \mathrm{Mp}$ \\
& 2 & $\mathrm{~A} / \mathrm{C}$ & $\mathrm{M}$ \\
& 3 & $\mathrm{M}$ & $\mathrm{S} / \mathrm{Mp}$ \\
\hline \multirow{2}{*}{ II } & & & $\mathrm{A} / \mathrm{Mp}$ \\
& 5 & $\mathrm{~S}$ & $\mathrm{M}$ \\
& 6 & $\mathrm{M}$ & $\mathrm{S}$ \\
\hline & & & \\
\hline III & 7 & $\mathrm{~S}$ & $\mathrm{~A}$ \\
& 8 & $\mathrm{~A}$ & $\mathrm{M}$ \\
& 9 & $\mathrm{M}$ & $\mathrm{S}$ \\
\hline & & & $\mathrm{A}$ \\
\hline & 10 & $\mathrm{~A}$ & $\mathrm{~S}$ \\
& 11 & $\mathrm{M}$ & $\mathrm{M}$ \\
\hline
\end{tabular}

A: Arroz; C: Crotalária júncea; M: Milho; S: Soja; Mp: Mucuna preta

Tabela 2. Rendimento de fitomassa seca de Crotalaria juncea e mucuna preta desenvolvidas no outono-inverno de 1999 e 2000, após seqüência de culturas de verão em Pindorama, SP.

\begin{tabular}{ccc}
\hline Seqüência de culturas & $\begin{array}{c}\text { Crotalaria } \\
\text { juncea }\end{array}$ & $\begin{array}{c}\text { Mucuna } \\
\text { preta (Mp) }\end{array}$ \\
\cline { 2 - 3 } & 1999 & 2000 \\
\hline Arroz/Crotalária - Milho - Soja/Mucuna preta & 1500 & 7920 \\
Milho - Soja/Crotalária - Arroz/Mucuna preta & 1482 & 6795 \\
Milho - Soja- Arroz/Mucuna preta & 1449 & 6290 \\
\hline
\end{tabular}

No florescimento das plantas de soja, arroz e milho, efetuaram-se amostragens de folhas, para determinação dos teores de nutrientes.

Os rendimentos de grãos foram determinados nas quatro linhas centrais das parcelas com soja e arroz e nas três de milho, excluindo-se $0,5 \mathrm{~m}$ em cada extremidade. A fitomassa verde e seca da crotalária foi 
avaliada no florescimento pleno das plantas, em cinco sub-amostras de 1 $\mathrm{m}^{2}$ por parcela; para tal, as plantas foram cortadas rente à superfície do solo.

Coletaram-se amostras de solo após a colheita das culturas graníferas, para análise da fertilidade, sendo determinados $\mathrm{pH}, \mathrm{V} \%$, matéria orgânica, $\mathrm{P}, \mathrm{K}, \mathrm{Ca}$ e Mg, pelo método de Raij \& Quaggio (1983).

Os dados obtidos foram submetidos à análise de variância e aplicados o testes $\mathrm{F}$ aos níveis de $1 \%$ e $5 \%$ de probabilidade; os constrastes entre médias foram verificados pelo teste de Duncan ao nível de $5 \%$ de probabilidade.

\section{RESULTADOS E DISCUSSÃO}

Em função da severa incidência de nematóide de galha na área experimental, em março de 2000 , fez-se nova semeadura, substituindose a crotalária por outro adubo verde, a mucuna preta (Mucuna aterrima) que apresenta efeito nematicida (Cavaleri et al., 1963), comprovado por Mascarenhas et al. (1994). Os rendimentos de fitomassa seca de mucuna preta obtidos nessa época tardia de semeadura variaram entre 6.290 a $7.920 \mathrm{~kg} \cdot$ ha $^{-1}$ (Tabela 2), valores considerados adequados para o período considerado, embora correspondentes à metade daqueles relatados por Neme (1960), em cultivos estabelecidos em novembro.

A análise de variância dos dados de produtividade de soja está apresentada na Tabela 3. Por meio do teste $\mathrm{F}$ ao nível de probabilidade considerada na metodologia, verifica-se que não houve efeito dos tratamentos. Os rendimentos de grãos de soja em 1999/2000 foram maiores do que no segundo ano de cultivo (Tabela 4), devido, em parte, às adequadas temperaturas e distribuição de chuvas no período e também à característica de tolerância à acidez do solo do cultivar utilizado. Não se observaram diferenças estatísticas pelo teste de Duncan ao nível de 5\% de probabilidade entre os tratamentos, indicando a possibilidade do cultivo de soja, ano após ano, na mesma área, sem redução de sua produtividade e desde que não se verifique a incidência de doenças e pragas, como o nematóide nas raízes (Mascarenhas et al., 1993; 1998). 
Tabela 3. Quadro de análise de variância dos dados de produtividade de soja. Pindorama, SP. 2000/2001.

\begin{tabular}{lccccc}
\hline Causas da variação & G.L. & S.Q. & Q.M. & Valor F & Prob. $>$ F \\
\hline Tratamentos & 3 & 270066,5 & 90022,17 & 0,4937 & 0,698 \\
Bloco & 3 & 389448,5 & & & \\
Resíduo & 9 & 1640979,0 & 182331,0 & & \\
\hline Total & 15 & 2300494,0 & & & \\
\hline
\end{tabular}

Média geral $=2389 \quad \mathrm{CV}=17,9 \%$

Tabela 4. Rendimentos médios de grãos de soja, sob diferentes rotações de culturas e em monocultivo. Pindorama, SP. 1999/00 e $2000 / 01$.

\begin{tabular}{cccccccc}
\hline Seguiência & Ano 1 & Ano2 & Ano3 & $1999 / 2000$ & $2000 / 2001$ & Média & $\begin{array}{c}\text { Produção } \\
\text { Relativa }\end{array}$ \\
\hline I & A/C & M & S & $4197 \mathrm{a}$ & $2349 \mathrm{a}$ & 3273 & 95 \\
II & A/C & M & S & $3951 \mathrm{a}$ & $2285 \mathrm{a}$ & 3118 & 90 \\
III & A & M & S & $3811 \mathrm{a}$ & $2611 \mathrm{a}$ & 3211 & 93 \\
IV & S & S & S & $4610 \mathrm{a}$ & $2312 \mathrm{a}$ & 3461 & 100 \\
\hline CV\% & & & & 18,1 & 17,87 & & \\
\hline
\end{tabular}

* Médias seguidas por letras distintas nas colunas diferem entre si pelo teste de Duncan a $5 \%$.

A: Arroz; C: Crotalária júncea; M: Milho; S: Soja

Em ambos os anos agrícolas (1999/2000 e 2000/2001) os rendimentos de grãos de milho nas três primeiras sequiências foram superiores aos do monocultivo. Os valores de produção relativa média nos dois anos foram 34 a $47 \%$ superiores ao da testemunha (Tabela 5). Dentre os tratamentos de rotação, na sequiência de cultivos II- S-A/C-M obteve-se a melhor produção relativa média, embora sem diferenças estatísticas com os tratamentos das sequiências I e III. Destaca-se, ainda, o rendimento do 
milho no tratamento S-A-M, indicativo do bom desempenho dessa gramínea, mesmo após o cultivo de outra cultura da mesma família botânica na seqüência rotacional estabelecida.

A baixa produtividade observada na testemunha pode ser devida a uma possível intolerância ao cultivo contínuo, embora seja um valor superior ao da média observada no Estado de São Paulo (3.500 kg.ha-1).

A produção de uma cultura é resultado da interação dela mesma com o ambiente. Assim, os rendimentos de arroz observados no ano 1999/ 2000 podem ser considerados elevados (Tabela 6 ), se comparados aos do ano subsequiente, provavelmente devidos às adequadas temperaturas e distribuição de chuvas, principalmente no florescimento e enchimento de grãos, assim como à provável tolerância do cultivar à acidez do solo, embora não houvesse diferenças significativas entre os tratamentos. Em relação a esse ano agrícola, os rendimentos de arroz no ano 2000/2001 foram inferiores (Tabela 6 ), devidos provavelmente aos efeitos climáticos negativos na fase reprodutiva, com ocorrência de veranico e de elevadas temperaturas em meados de janeiro . O efeito das rotações foi acentuado nas seqüências I, II e III, sendo obtidos valores de rendimento estatisticamente superiores aos da testemunha, porém não entre si..

Os rendimentos do arroz em rotação foram praticamente o dobro dos da testemunha, indicando ser adequada a seqüência arroz após leguminosas. A acentuada redução na produtividade do arroz em monocultivo está possivelmente relacionada ao efeito alelopático aparentemente mais severo do que o observado no milho. Conforme os dados da produção relativa nos dois anos, tem-se que o melhor tratamentc foi M-S/Mp-A seguido por M-S-A.

De acordo com os resultados da análise de nutrientes nas folhas no ano 1999/2000, para as culturas de soja, milho e arroz (Tabela 7) verifica-se que os elementos estão em quantidades adequadas, segundo Cantarella et al. (1996) e Ambrosano et al. (1996). Isso é indicativo de que o suprimento de nutrientes no solo foi suficiente para o atendimente das necessidades das plantas, nesse nível de tecnologia adotado.

Embora tenha sido aplicado o calcário dolomítico para elevaçã da saturação por bases a 50\% no início do ciclo de 1999, observa-se 
Tabela 5. Rendimentos médios de grãos de milho sob diferentes rotações de culturas e em monocultivo. Pindorama, SP. 1999/00 e 2000/01.

\begin{tabular}{|c|c|c|c|c|c|c|c|}
\hline Seqüência & Ano 1 & Ano2 & Ano3 & $1999 / 2000$ & $2000 / 2001$ & Média & $\begin{array}{l}\text { Produção } \\
\text { Relativa }\end{array}$ \\
\hline & & & & & $---k g \cdot h a^{-1} \ldots$ & …... & $\%$ \\
\hline I & $\mathrm{S} / \mathrm{C}$ & $\mathrm{A} / \mathrm{Mp}$ & M & $5914 a^{*}$ & $8497 a$ & 7206 & 134 \\
\hline II & $\mathrm{S}$ & $\mathrm{A} / \mathrm{Mp}$ & M & $6398 \mathrm{a}$ & $9405 a$ & 7902 & 147 \\
\hline III & $S$ & A & M & $6464 a$ & $8085 a$ & 7275 & 135 \\
\hline IV & $\mathrm{M}$ & $\mathrm{M}$ & $\mathrm{M}$ & $4509 b$ & $6270 \mathrm{~b}$ & 5390 & 100 \\
\hline CV\% & & & & 11,97 & 14,0 & & \\
\hline
\end{tabular}

*Médias seguidas por letras distintas nas colunas diferem entre si pelo teste de Duncan a $5 \%$.

A: Arroz; C: Crotalária júncea; M: Milho; S: Soja; Mp: Mucuna preta

Tabela 6. Rendimentos médios de grãos de arroz sob diferentes rotações de culturas e em monocultivo. Pindorama 1999/00 e 2000/01.

\begin{tabular}{|c|c|c|c|c|c|c|c|}
\hline Seqüência & Ano 1 & Ano2 & Ano3 & $1999 / 2000$ & $2000 / 2001$ & Média & $\begin{array}{l}\text { Produção } \\
\text { Relativa }\end{array}$ \\
\hline & & & & 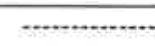 & $\mathrm{kg} \cdot \mathrm{ha}^{-1} \ldots$ & n...... & $\%$ \\
\hline I & M & $\mathrm{S} / \mathrm{Mp}$ & A & $5148 a^{*}$ & $2361 \mathrm{a}$ & 3755 & 166 \\
\hline II & M & $S$ & A & $4347 a$ & $2667 a$ & 3507 & 155 \\
\hline III & M & $S$ & A & $4074 a$ & $2220 \mathrm{a}$ & 3147 & 139 \\
\hline IV & A & A & A & $3383 a$ & $1137 \mathrm{~b}$ & 2260 & 100 \\
\hline $\mathrm{CV} \%$ & & & & 24,83 & 18,0 & & \\
\hline
\end{tabular}

*Médias seguidas por letras distintas nas colunas diferem entre si pelo teste de Duncan a $5 \%$.

A: Arroz; Mp: Mucuna preta; M: Milho; S: Soja ;

pelos dados da Tabela 8 , que a correção não foi satisfatória. Isso porque se tem um valor de saturação por bases ainda baixo, logo após a colheita, talvez devido à qualidade do corretivo utilizado, com PRNT abaixo do recomendado ou, ainda, pela maior lixiviação dos cátions Ca e $\mathrm{Mg}$ normalmente observada em solos de textura arenosa.. Verificou-se, também, maior extração desses nutrientes pelo arroz, com reflexos diretos no bai- 
Tabela 7. Teores de N, P, K, Ca e Mg em folhas de soja, milho e arroz, em Pindorama, SP.1999/2000.

\begin{tabular}{|c|c|c|c|c|c|c|c|c|}
\hline \multirow[t]{2}{*}{ Seqüência } & \multicolumn{3}{|c|}{ Tratamentos } & \multirow[t]{2}{*}{$\mathrm{N}$} & \multirow[t]{2}{*}{$\mathrm{P}$} & \multirow[t]{2}{*}{$\mathrm{K}$} & \multirow[t]{2}{*}{$\mathrm{Ca}$} & \multirow[t]{2}{*}{$\mathrm{Mg}$} \\
\hline & Anol & Ano2 & Ano3 & & & & & \\
\hline \multicolumn{9}{|c|}{ MILHO } \\
\hline I & $\mathrm{S} / \mathrm{C}$ & $\mathrm{A} / \mathrm{Mp}$ & M & 28,6 & 3,2 & 20,3 & 3,7 & 2,3 \\
\hline II & $\mathrm{S}$ & $\mathrm{A} / \mathrm{Mp}$ & M & 29,6 & 3,1 & 20,3 & 3,5 & 2,1 \\
\hline III & $S$ & A & M & 28,9 & 3,1 & 20,9 & 4,4 & 2,4 \\
\hline IV & $\mathrm{M}$ & $\mathrm{M}$ & $\mathrm{M}$ & 27,1 & 3,4 & 19,7 & 3,7 & 2,6 \\
\hline \multicolumn{9}{|c|}{ ARROZ } \\
\hline I & $\mathrm{M}$ & $\mathrm{S} / \mathrm{Mp}$ & $\mathrm{A} / \mathrm{C}$ & 20,3 & 4,8 & 32,7 & 4,4 & 4,7 \\
\hline II & M & $\mathrm{S}^{1}$ & $\mathrm{~A} / \mathrm{C}$ & 27,6 & 4,2 & 32,3 & 3,7 & 3,9 \\
\hline III & M & $S$ & A & 28,2 & 5,1 & 32,7 & 4,9 & 4,5 \\
\hline IV & A & A & A & 24,2 & 3,6 & 29.5 & 4,5 & 4,2 \\
\hline \multicolumn{9}{|c|}{ SOJA } \\
\hline I & $\mathrm{A} / \mathrm{C}$ & M & $S$ & 39,6 & 4,5 & 28,1 & 17,9 & 6,6 \\
\hline II & $\mathrm{A} / \mathrm{C}$ & M & $S$ & 40,3 & 4,5 & 27,7 & 10,7 & 6,2 \\
\hline III & A & $\mathrm{M}$ & $\mathrm{S}$ & 36,0 & 5,1 & 28,9 & 16,1 & 7,1 \\
\hline IV & $S$ & $S$ & $\mathrm{~S}$ & 44,2 & 4,8 & 26,7 & 13,7 & 6,1 \\
\hline
\end{tabular}

A: Arroz; C: Crotalária júncea; M: Milho; S: Soja; Mp: Mucuna preta

xo valor da saturação por bases nessas áreas. Por outro lado, mesmo com as condições de solo e clima favoráveis à queima do carbono, de acordo com a análise realizada em 2000, o teor de matéria orgânica no solo foi duas vezes maior e o de fósforo quase três vezes maior, quando comparado aos dados observados nessa área em 1991, que eram $10,0 \mathrm{~g} \cdot \mathrm{dm}^{-3} \mathrm{e}$ $11,0 \mathrm{mg} \cdot \mathrm{dm}^{-3}$, respectivamente, para a matéria orgânica e P. Naquela ocasião, o $\mathrm{pH}\left(\mathrm{CaCl}_{2}\right)$ era de 4,5 , a saturação por bases $34 \%$ e os teores de $\mathrm{K}$, $\mathrm{Ca}$ e $\mathrm{Mg}$ eram 0,7; 3,7 e 2,0 $\mathrm{mmol}_{\mathrm{c}} \cdot \mathrm{dm}^{-3}$ respectivamente.

Como era de esperar, houve uma gradação nos teores dos elementos no solo. Para os cátions móveis como o $\mathrm{K}^{+} \mathrm{e} \mathrm{Mg}^{2+}$, observaramse teores muito baixos a baixos, provavelmente em função da lixiviação deles para camadas profundas do perfil do solo, enquanto que o de $\mathrm{Ca}^{2+}$ era médio, conforme Raij et al. (1996). A acidez da camada arável do solo encontrava-se alta a média, na maioria dos tratamentos e culturas, possivelmente como influência da baixa eficiência da correção efetuada. 
Tabela 8. Resultados da análise química de um Argissolo Vermelho Amarelo, à profundidade de $0-20 \mathrm{~cm}$, após a colheita de culturas. Pindorama, SP. 1999/2000.

\begin{tabular}{|c|c|c|c|c|c|c|c|c|c|c|c|}
\hline \multirow{2}{*}{ Sequência } & \multicolumn{3}{|c|}{ Tratamentos } & \multirow{2}{*}{$\begin{array}{c}\mathrm{PH} \\
\mathrm{CaCl}_{2}\end{array}$} & \multirow[t]{2}{*}{ V } & \multirow{2}{*}{$\begin{array}{l}\text { Mat. } \\
\text { Orgân. }\end{array}$} & \multirow[t]{2}{*}{$\mathrm{P}$} & \multirow[t]{2}{*}{$\mathrm{K}$} & \multirow[t]{2}{*}{$\mathrm{Ca}$} & \multirow[t]{2}{*}{$\mathrm{Mg}$} & \multirow[t]{2}{*}{$\mathrm{H}+\mathrm{Al}$} \\
\hline & Ano 1 & Ano 2 & Ano 3 & & & & & & & & \\
\hline & & & & & $\%$ & g.dm ${ }^{3}$ & $\mathrm{mg.dm}^{-3}$ & $\ldots . .$. & $\cdots m n$ & $\mathrm{l}_{c} \cdot \mathrm{dm}$ & $\ldots \ldots \ldots$ \\
\hline \multicolumn{12}{|c|}{ MILHO } \\
\hline I & $\mathrm{S} / \mathrm{C}$ & $\mathrm{A} / \mathrm{Mp}$ & M & 4,8 & 30 & 20,0 & 36,9 & 0,6 & 4,8 & 2,5 & 19,7 \\
\hline II & $S$ & $\mathrm{~A} / \mathrm{Mp}$ & M & 4,7 & 28 & 18,6 & 40,6 & 1,0 & 4,3 & 2,1 & 19,4 \\
\hline III & $\mathrm{S}$ & A & M & 4,5 & 31 & 23,2 & 36,1 & 0,9 & 4,9 & 3,0 & 18,2 \\
\hline IV & M & M & M & 5,1 & 35 & 30,3 & 38,1 & 0,6 & 5,9 & 3,0 & 16,3 \\
\hline \multicolumn{12}{|c|}{ ARROZ } \\
\hline I & $\mathrm{M}$ & $\mathrm{S} / \mathrm{Mp}$ & A & 4,6 & 27 & 19,6 & 47,4 & 1,0 & 4,5 & 1,3 & 20,3 \\
\hline II & M & S & A & 4,4 & 22 & 25,0 & 46,4 & 0,9 & 3,6 & 1,5 & 23,4 \\
\hline III & M & $S$ & A & 4,1 & 19 & 20,0 & 45,9 & 0,8 & 3,0 & 1,3 & 24,2 \\
\hline IV & A & A & A & 4,4 & 19 & 20,0 & 46,5 & 0.8 & 5,7 & 1,3 & 23,6 \\
\hline \multicolumn{12}{|c|}{ SOJA } \\
\hline I & $\mathrm{A} / \mathrm{C}$ & $\mathrm{M}$ & $S$ & 5,0 & 32 & 22,0 & 38,0 & 0,5 & 5,0 & 2,3 & 19,9 \\
\hline II & $\mathrm{A} / \mathrm{C}$ & M & $S$ & 4,8 & 30 & 20,0 & 40,6 & 0,8 & 4,0 & 2,0 & 21,5 \\
\hline III & A & M & $S$ & 4,6 & 30 & 23,9 & 38,5 & 0,9 & 5,0 & 3,2 & 19,8 \\
\hline IV & $\mathrm{S}$ & $\mathrm{S}$ & $S$ & 5,2 & 34 & 30,6 & 41,2 & 0,7 & 5,7 & 3,4 & 15,4 \\
\hline
\end{tabular}

A: Arroz; C: Crotalária júncea; M: Milho; S: Soja; Mp:Mucuna preta

Os resultados da análise foliar para macro e micronutrientes no ano 2000-2001 encontram-se nas Tabelas 9 e 10 respectivamente. Os teores de $\mathrm{N}, \mathrm{P}, \mathrm{K}$ e $\mathrm{Mg}$ nas folhas de milho estavam adequados enquanto que o de $\mathrm{Ca}$, nos tratamentos S/C/A/Mp/M, S/A/M e M-M-M, estava aquém do nível adequado; todavia, não o suficiente para que se manifestasse sintoma de deficiência aparente na planta e para que o rendimento fosse negativamente afetado. Os teores de macronutrientes nas plantas de soja e arroz também encontravam-se adequados.

Em relação aos teores de micronutrientes, estes podem ser considerados suficientes nas plantas de milho, enquanto que, nas de soja e arroz, apenas o teor de $\mathrm{Mn}$ era alto a muito alto, mas ainda não prejudicial à produtividade das culturas. Constata-se, assim, a tolerância ao Mn e à acidez do solo nos cultivares utilizados dessas culturas (Camargo \& Camargo, 1985; Mascarenhas et al.; 1990; Mascarenhas et al., 1998). 
Tabela 10. Teores de $\mathrm{B}, \mathrm{Cu}, \mathrm{Fe}, \mathrm{Mn}$ e $\mathrm{Zn}$ em folhas de soja, milho e arroz em Pindorama, SP. 2000/01.

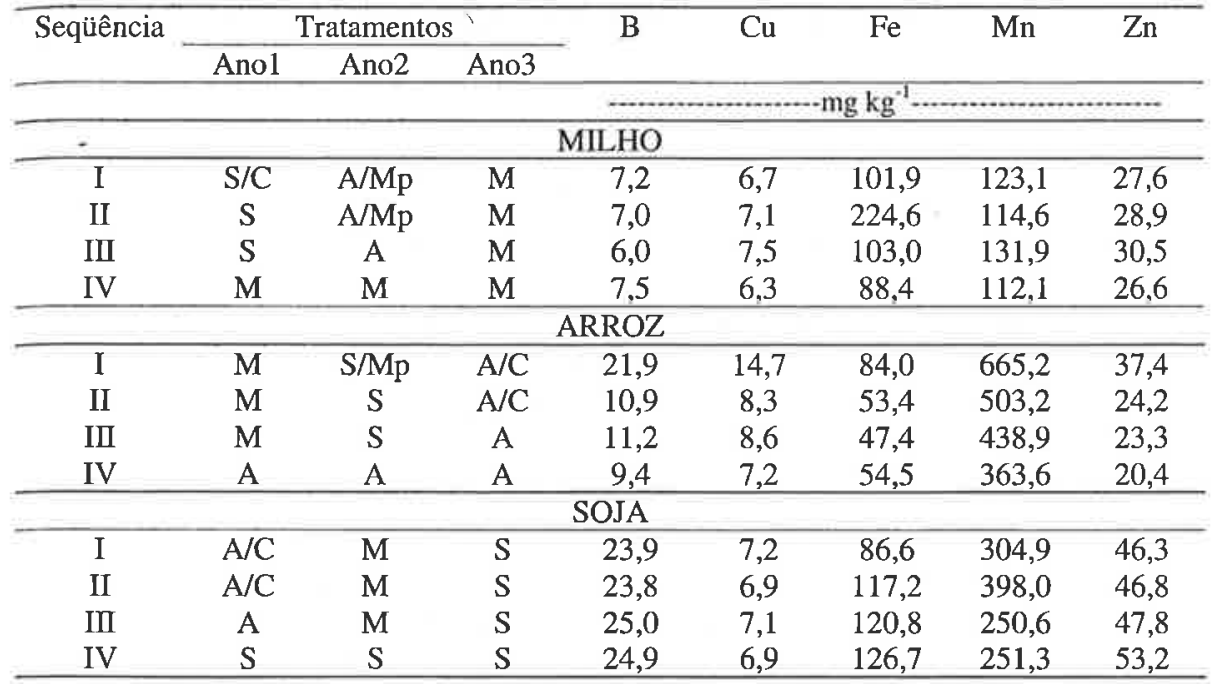

A: Arroz; C: Crotalária júncea; M: Milho; S: Soja; Mp: Mucuna preta

nados na análise foliar (Tabela 9). No entanto, tratando-se de elementos finitos no solo, passíveis de não reposição, futuramente também poderá ocorrer deficiência nas plantas. Como conseqüência do baixo teor de cátions trocáveis observaram-se baixa saturação por bases e alta acidez do solo; no entanto, como os cultivares utilizados eram tolerantes, houve pouca influência sobre os rendimentos de grãos das culturas.

\section{CONCLUSÕES}

1. Com a rotação de culturas é viável a manutenção e até o incremento da produtividade das gramíneas graníferas, arroz e milho, sendo reduzidos possíveis efeitos alelopáticos;

2. A produtividade da cultura de soja não é aumentada com rotações anuais com arroz, milho e adubo verde;

3. A utilização de cultivares de soja, milho e arroz tolerantes à acidez é muito importante no manejo das culturas em solos de baixa fertilidade. 
Tabela 11. Resultados da análise química da camada arável de um Argissolo vermelho amarelo, à profundidade de $0-20 \mathrm{~cm}$, após a colheita das culturas. Pindorama, SP. 2000/2001.

\begin{tabular}{|c|c|c|c|c|c|c|c|c|c|c|c|}
\hline \multirow[t]{2}{*}{ Seqüência } & \multicolumn{3}{|c|}{ Tratamentos } & \multirow{2}{*}{$\underset{\mathrm{CaCl}_{2}}{\mathrm{pH}}$} & \multirow[t]{2}{*}{ V } & \multirow[t]{2}{*}{ MO } & \multirow[t]{2}{*}{$\mathrm{P}$} & \multirow[t]{2}{*}{$\mathrm{K}$} & \multirow[t]{2}{*}{$\mathrm{Ca}$} & \multirow[t]{2}{*}{$\mathrm{Mg}$} & \multirow[t]{2}{*}{$\mathrm{H}+\mathrm{AL}$} \\
\hline & Ano 1 & Ano 2 & Ano 3 & & & & & & & & \\
\hline & & & & & $\%$ & g.dm ${ }^{3}$ & mg.dm ${ }^{-3}$ & \multicolumn{4}{|c|}{$\ldots \ldots \ldots m_{0} m_{c} \cdot \mathrm{dm}^{-3} \ldots \ldots \ldots$} \\
\hline \multicolumn{12}{|c|}{ MILHO } \\
\hline I & $\mathrm{S} / \mathrm{C}$ & $\mathrm{A} / \mathrm{Mp}$ & M & 4,6 & 24 & 9,5 & 34,0 & 0,5 & 3,2 & 2,0 & 18,2 \\
\hline II & $S$ & $\mathrm{~A} / \mathrm{Mp}$ & M & 4,5 & 25 & 8,7 & 34,2 & 0,7 & 2,5 & 1,3 & 20,7 \\
\hline III & $\mathrm{S}$ & A & M & 4,7 & 23 & 8,5 & 32,7 & 0,8 & 2,7 & 1.5 & 18,0 \\
\hline IV & $\mathrm{M}$ & M & $\mathrm{M}$ & 4,9 & 23 & 9,7 & 30,5 & 0,7 & 2,7 & 1,5 & 17,5 \\
\hline \multicolumn{12}{|c|}{ ARROZ } \\
\hline $\mathrm{I}$ & $\mathrm{M}$ & $\mathrm{S} / \mathrm{Mp}$ & $\mathrm{A} / \mathrm{C}$ & 4,6 & 19 & 9,7 & 31,5 & 0,7 & 2,5 & 1,2 & 19,2 \\
\hline II & M & $\mathrm{S}$ & $\mathrm{A} / \mathrm{C}$ & 4,5 & 16 & 6,2 & 34,7 & 0,6 & 2,5 & 1,0 & 18,0 \\
\hline III & M & S & $\mathrm{A}$ & 4,9 & 26 & 9,0 & 33,2 & 0,6 & 3,2 & 2,2 & 16,7 \\
\hline IV & A & A & A & 4,6 & 18 & 10,5 & 38,0 & 0,5 & 2,0 & 1,7 & 18,2 \\
\hline \multicolumn{12}{|c|}{ SOJA } \\
\hline I & $\mathrm{A} / \mathrm{C}$ & M & $S$ & 4,8 & 25 & 9,2 & 36,7 & 0,7 & 3,7 & 2,2 & 17,2 \\
\hline II & $\mathrm{A} / \mathrm{C}$ & M & $S$ & 4,9 & 27 & 10,0 & 36,0 & 0,8 & 3,5 & 2,7 & 15,7 \\
\hline III & $\mathrm{A}$ & $\mathrm{M}$ & $S$ & 5,2 & 28 & 10,0 & 35,2 & 0,8 & 2,7 & 2,2 & 17,5 \\
\hline IV & $S$ & $S$ & $S$ & 5,0 & 29 & 10,2 & 36,2 & 0,8 & 3.7 & 2.0 & 15,7 \\
\hline
\end{tabular}

A: Arroz; C: Crotalária júncea; M: Milho; S: Soja; Mp: Mucuna preta

\section{REFÊRENCIAS BIBLIOGRÁFICAS}

AMBROSANO E.J.; TANAKA, R.T.; MASCARENHAS, H.A.A. ; RAIJ, B.van; QUAGGIO, J.A.; CANTARELLA, H. Leguminosas e Oleaginosas. In: RAIJ, B.van, CANTARELLA, H., QUAGGIO, J.A. e FURLANI, A.M.C. Recomendações de adubação e calagem para o Estado de São Paulo. $2^{2}$ ed. Campinas, Instituto Agronômico \& Fundação IAC, 1996, Boletim 100, 285p.

CANTARELLA, H. \& RAIJ, B. van. Cereais. In: RAIJ, B.van, CANTARELLA, H., QUAGGIO, J.A. e FURLANI, A.M.C. Recomendação de adubação e calagem para o Estado de São Paulo. Campinas, 1996, Boletim 100, 285p.

CAMARGO, C.E.O. \& CAMARGO, O.B.A. Estudo comparativo de tolerância à toxidez de ferro e alumínio em arroz. Bragantia, Campinas, 44:97-114, 1985.

CARGILL Sementes híbridas, Campinas: Fundação Cargill, 91p, 1996. 
im

Ós

CAVALERI, P.A.; FUZZATO, M.F.; FREIRE, E.S. Adubação do algodoeiro. XIV - Experiências com mucuna e adubos minerais. Bragantia, 22(26): 331-350, 1963.

EMBRAPA. Sistema brasileiro de classificação de solos, Brasília, Embrapa Produção de Informação; Embrapa Solos, Rio de Janeiro, 1999. 412p. MASCARENHAS, H.A.A.;MIRANDA, M.A.C.;TANAKA, R.T.;FALIVENE, S.M.P.; DECHEN, A.R. Comportamento de cultivares precoces de soja em solução nutritiva, contendo diferentes níveis de manganês. Pesquisas Agropecuária Brasileira, Brasília, 25(4):600-615,1990.

MASCARENHAS, H.A.A.; NAGAI, V.; GALLO, P.B.; PEREIRA, J.C.V.N.A.; TANAKA, R.T. Sistema de rotação de culturas de milho, algodão e soja e seu efeito sobre a produtividade. Bragantia, Campinas, 52 (1): 53-61, 1993.

MASCARENHAS, H.A.A.; TANAKA, R.T.; COSTA,A.A.;ROSA, F.V.;COSTA, V.F. Efeito residual de leguminosas sobre rendimento físico e econômico da cana-planta. Campinas, Instituto Agronômico, 1994, 15p (Boletim Científico n⿳3032).

NEME, N.A. Ensaios comparativos de adubos verdes. Instituto Agronômico (Campinas). Relatório da Seção de Leguminosas 1958/59, 10p (Datilografado).

MASCARENHAS, H.A.A.; NOGUEIRA, S. dos S.S.; TANAKA, R.T; MARTINS, A.L.M.; CARMELLO, Q.A.C. Efeito na produtividade da rotação das culturas de verão e crotalária no inverno. Scientia Agricola, Piracicaba, 55(3): 536-537, set/dez/ 1998.

RAIJ, B. van \& QUAGGIO, J. A. Métodos de análise de solo para fins de fertilidade. Campinas: Instituto Agronômico, 1983. 31p (Boletim Técnico,83).

RAIJ, B.van; QUAGGIO, J.A.; CANTARELLA, H.E.; ABREU, C.A. Representação dos resultados de análises de solo, folhas, fertilizantes e corretivos. In: RAIJ, B.van, CANTARELLA, H., QUAGGIO, J.A. e FURLANI, A.M.C. Recomendações de adubação e calagem para o Estado de São Paulo. $2^{\mathfrak{a}}$ ed. Campinas, Instituto Agronômico \& Fundação IAC, 1996, Boletim 100, 285p.

WUTKE, E. B. Desempenho do feijoeiro em rotação com milho e adubos verdes. ESALQ/USP, Piracicaba, 1998, 146p.Tese (Doutorado). 